\title{
Design: um facilitador na experiência visual do surdo na educação superior
}

\author{
Elisangela Tonelini Souza; \\ Ana Cláudia Maynardes
}

resumo:

O objetivo deste estudo é destacar a importância do design como um processo acessível e facilitador na experiência visual de estudantes surdos no ensino superior. Para isto, é importante que sejam compreendidas as barreiras e dificuldades enfrentadas por estes estudantes em sua vivêcia universitária. Foram apresentados alguns resultados de pesquisas, os quais evidenciam tanto a vivência universitária, quanto a experiência visual destes estudante. Os resultados descrevem a necessidade de um olhar sensível e desmistificador acerca da aliança do design às práticas pedagógicas voltadas para a educação dos surdos, até então focadas em territórios exclusivamente ouvintes. Ademais, entende-se que o design, pode atuar sim, como propulsor da experiência visual do surdo, assim como, um mediador das interações relacionais entre todos os envolvidos neste processo educacional.

palavras-chave: design; educação inclusiva; experiência visual, surdez; ensino superior. 


\section{Introdução}

Este estudo tem como objetivo, expor a assertividade do design como um processo facilitador na experiência visual do surdo, assim como, apresentar resultados de pesquisas que mostram alguns desafios e necessidades deste aluno no ensino superior.

A educação inclusiva envolvendo os surdos tem sido objeto de estudo em diferentes esferas, assim, o interesse pelo tema surgiu mediante um estudo com foco na acuidade de uma inter-relação mais participativa do design como processo acessível e facilitador na experiência visual dos surdos enquanto acadêmicos.

Este artigo, apresenta alguns estudos e pesquisas de campo envolvendo tanto a educação inclusiva, quanto a relevância dos artefatos na experiência visual dos surdos. Tais estudos e pesquisas, elucidam a importância de um conhecimento aprofundado acerca das experiências vivenciadas pelo aluno surdo no contexto acadêmico, pois este conhecimento, servirá como ponto de partida para que sejam exploradas questões relevantes na educação inclusiva destes alunos, e assim obter possíveis soluções, para que sejam atendidas suas reais necessidades.

A adaptação do indivíduo surdo ao contexto em que está inserido, também é relevante para o bom desenvolvimento deste processo educacional inclusivo, pois quando o surdo se sente realmente 'integrado', conectado com sua identidade, ele deixa aflorar seus sentidos e coloca em prática seu senso de percepção, o que favorece sua experiência visual e relacional. Nesse sentido, após avaliar tais estudos e compreender os principais desafios e necessidades enfrentados pelos surdos e demais envolvidos no processo educacional de nível superior, o foco será destacar o design como um processo facilitador.

Foram destacados alguns estudos e pesquisas de campo, os quais geraram um levantamento de dados. Tais levantamentos, indicam a necessidade de uma percepção singular acerca de sugestões assertivas para uma educação plural e efetiva do surdo, livre de segregação, que realmente abrace a causa do surdo na luta pelo reconhecimento de sua cultura e pela apropriação de seu espaço identitário. Mesmo com tamanhas deficiências e fragilidades ainda existentes neste processo educacional inclusivo, é importante que sejam repensadas estratégias envolvendo a questão didática, político-pedagógica, o investimento em pesquisas e a infraestrutura das instituições, a fim de atender às especificidades relativas à surdez. Ademais, também observou-se como o design, através de suas múltiplas facetas, mostra-se um grande aliado na experiência visual do surdo e demais envolvidos neste processo educacional.

\section{A inclusão de surdos no ensino superior e seus desafios}

As pesquisas envolvendo a educação superior de surdos no Brasil vêm pautando seus esforços acerca dos gargalos existentes no processo educacional de surdos, nas práticas pedagógicas, na compreensão de sua vivência universitária e trajetória escolar, e em suas relações/interações com educadores, colegas e demais profissionais envolvidos neste processo.

É fato que, o processo de inclusão de surdos no contexto educacional em nível superior, até então voltado para o 'mundo ouvinte', infelizmente ainda apresenta-se um processo complexo e dotado de um método inibidor de segregação gritante, que envolve algumas questões que têm impacto direto na experiência educacional do surdo e na interação entre surdos e ouvintes, tais como: a) cultura e identidade surda; b) dificuldade comunicacional (língua de sinais); c) projeto político-pedagógico; d) dificuldades didáticas/metodológicas; d) estrutura das instituições; e outras.

Para se efetivar no cotidiano da sala de aula, a inclusão pressupõe mais do que a promulgação de leis ou a boa vontade dos educadores e profissionais ligados ao processo educativo. É na sala de aula, no convívio com o professor e com os colegas que a inclusão poderá se tornar uma realidade para o aluno, ou não. Transformar uma política em uma prática requer o reposicionamento de todos os agentes envolvidos no processo educativo. (VALENTINI; BISOL, 2012:75)

Ademais, vale destacar como Valentini; Bisol (2012:11), em termos gerais, ainda elucidam sua percepção acerca de como certas didáticas, acabam por produzir "reflexos concretos na vida acadêmica dos estudantes". Sob essa perspectiva, Valentini; Bisol (2012:74) destacam quão 
importante é o papel das instituições em "repensar suas estratégias e investir em pesquisas que contribuam para um maior entendimento dos desafios e para a criação de contextos que favoreçam os processos inclusivos."

Valentini; Bisol (2012:43), relatam que, no período entre (2003-2005), houve um aumento expressivo de alunos surdos no contexto universitário. Em 2003, contatou-se um aumento de 27,39\% em 2003 - um total de "665 surdos frequentavam a universidade". Em 2005, "esse número havia aumentado para 2.428 surdos inseridos em universidades brasileiras públicas e privadas". Diante dos dados apresentados, também se torna relevante apresentar os últimos dados obtidos através do Censo da Educação Superior, para que seja demonstrado como vem acontecendo o acesso do surdo ao ensino superior, com foco nos limites e nos avanços das políticas educacionais de inclusão.

O Gráfico 1, mostra um comparativo com o quantitativo de alunos surdos matriculados e concluintes no ensino superior no Brasil, no período entre 2015-2017.

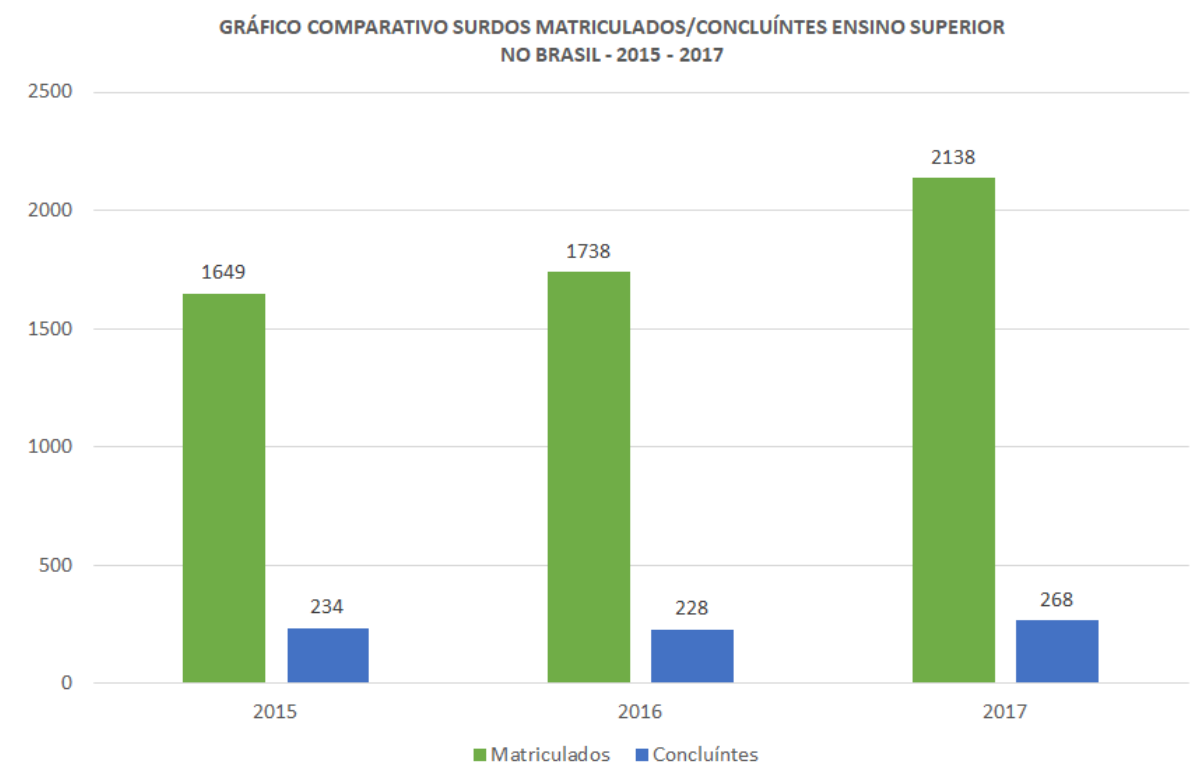

Gráfico 1: Comparativo surdos matriculados/concluintes ensino superior no Brasil.

Fonte: Elaborado pela autora mediante dados ordenados pelo Deed/Inep com base nos dados do Censo da Educação Superior.

Nota-se que neste triênio, a média de surdos matriculados é de 1.842 alunos, e concluintes é de 247 alunos. Valentin; Bisol (2012:21) afirmam que, "não basta o surdo ter o direito de ingressar na universidade, precisa também ter condições para nela permanecer."

Já o Gráfico 2, apresenta um comparativo entre total de alunos totais/surdos ingressantes no ensino superior no Brasil, no período entre 2015-2017. 


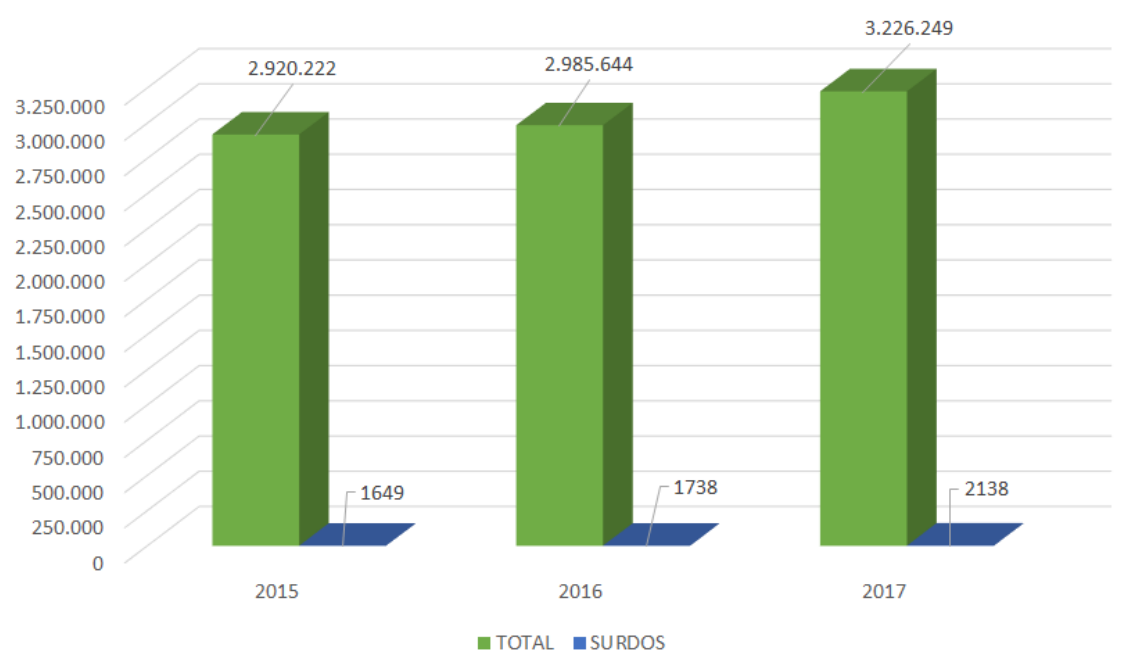

Gráfico 2: Comparativo alunos totais/surdos ingressantes no ensino superior no Brasil.

Fonte: Elaborado pela autora mediante dados ordenados pelo Deed/Inep com base nos dados do Censo da Educação Superior.

Diante disto, observa-se que, infelizmente, mesmo com o ingresso do surdo no ensino superior, ainda há um grande paradigma a ser quebrado: além de um vasto conhecimento acerca das barreiras e dificuldades enfrentadas pelo surdo, é importante que sejam apresentadas propostas de soluções assertivas e eficazes, que alavanquem o processo educacional deste aluno, favorecendo sua permanência na instituição, de forma que, o número de alunos surdos concluintes no ensino superior, seja cada vez mais crescente e equiparável ao número de ingressantes.

Sobretudo, não basta apenas uma vasta compreensão acerca destes desafios e barreiras, é importante ir além, pois tanto o educador, quanto os demais agentes envolvidos, devem estar dispostos a repensarem suas posturas, suas estratégias didático-pedagógicas e atuarem como participares ativos neste processo educacional inclusivo.

Uma gama complexa de aspectos deve ser considerada ao analisarmos a situação do jovem surdo que ingressa no Ensino Superior. No mínimo, devemos atentar para sua trajetória escolar pregressa e para o contexto institucional no qual ele busca inserir-se para dar seguimento aos seus estudos. (...) Em relação à identidade surda, estar em um ambiente onde a surdez e a comunicação visual não são a regra exige muito do jovem estudante surdo. Se por um lado essa experiência sobrecarrega o estudante cognitiva, emocional e socialmente, por outro lado possibilita novos olhares sobre suas vivências anteriores, antes mais restritas à comunidade surda. Se as instituições de Ensino Superior puderem dar o apoio necessário para que a experiência acadêmica seja bem sucedida, os jovens surdos poderão ter experiências positivas em um contexto de diversidade e heterogeneidade. (VALENTIN; BISOL, 2012:71,71)

Para Valentin; Bisol (2012:21), “conhecer as especificidades relativas à surdez e desmistificar ideias de senso comum poderá contribuir para a permanência e o sucesso da formação do acadêmico surdo." Para o surdo, falar tão somente de 'inclusão', é o mesmo que tratá-lo como deficiente, ou seja, é coloca-o em uma condição de submissão frente aos ouvintes, quando na verdade, sua luta envolve a busca pela 'acessibilidade', que acaba por oportunizar a este, segundo Valentin; Bisol (2012:47) "a construção do conhecimento em patamares semelhantes aos dos ouvintes."

Valentin; Bisol (2012:53), realizaram uma pesquisa de campo em cursos de graduação de uma universidade do sul do Brasil, em que participaram, voluntariamente, cinco estudantes com surdez profunda pré ou perilingual, com faixa etária entre 21 e 27 anos. Dentre estes estudantes, três são do sexo feminino e dois do sexo masculino, ambos com matrículas trimestrais regulares, em cursos de 
graduação nesta universidade, e trajetória anterior totalmente vivenciada em escolas especiais bilíngues.

Após a coleta de dados na pesquisa de campo, as autoras estabeleceram três categorias para a organização dos resultados: a) vivência dos alunos surdos em ambiente majoritariamente ouvinte; b) as interações entre intérpretes e professores e a organização do espaço de ensino e aprendizagem; e c) os aspectos relacionados à leitura e à escrita. Ademais, sobre a primeira categoria, as autoras exploraram a relação entre surdo e ouvinte e a reafirmação identitária do surdo de forma a não destacar suas necessidades, mas sim, valorizar suas individualidades.

No Quadro 1, são apresentadas algumas evidências levantadas por Valentin; Bisol (2012) em sua pesquisa de campo.

CATEGORIA 1

VIVÊNCIA DOS ALUNOS SURDOS EM
AMBIENTE MAJORITARIAMENTE OUVINTE.
Ingresso na instituição de ensino superior -
surdo perde o 'conforto' da escola especial,
um lugar de estar com os iguais;
"Olhar" do ouvinte - "o lugar não tem cheiro
de surdo";

A questão da língua torna-se mais evidente e desafiadora;

Surdos são tratados como ouvintes - "mundo bipartido";

Esforço do surdo em se adaptar à "comunidade dos ouvintes";

Desafio em transitar entre a língua de sinais e a língua portuguesa (o que incide sobre tarefas de leitura e escrita);

Aluna surda considera o contexto das aulas como "aulas de ouvintes" e se coloca em uma posição de "luta para sobreviver";

Conhecimento sobre a surdez não explica totalmente as barreiras enfrentadas pelos surdos;

Instituições pouco preparadas para receber alunos surdos;

Surdos vistos como "deficientes" - percepções diferentes de alunos/professores ouvintes sobre surdos;

"A diversidade acaba por questionar conceitos de normalidade."
CATEGORIA 2

CATEGORIA 3

INTERAÇÕES INTÉRPRETES X PROFESSORES E ORGANIZAÇÃO DO ESPAÇO DE ENSINO E APRENDIZAGEM.

Surdos almejam mesmo contexto das escolas bilíngues - professores surdos ou que dominem mais a língua de sinais;

Surdos desejam faculdade própria para surdos - referência a universidade de Gallaudet em Washington;

Intérprete assume papel de mediador entre aluno surdo e professor $x$ aluno ouvinte;

Sem a presença do intérprete, comunicação pode ser interrompida, mas pode haver recursos compensatórios;

Jovens entrevistados consideram indispensável a presença do intérprete;

Alunos surdos relatam as dificuldades com a capacitação do profissional, que são evidenciadas no ensino superior devido as especificidades e complexidades das diferentes áreas de conhecimento - faltam sinais específicos - uso excessivo datilologia; Aluno surdo sente necessidade de questionar as dúvidas sobre o conteúdo mais de uma vez com o intérprete, que se irrita em algum

momento, deixando aluno surdo desmotivado - tendência a evasão;

Questão delicada sobre a disponibilidade do intérprete para mediar a comunicação entre aluno surdo e professor - de mediador passa a ser barreira;

Dinâmica em sala de aula também é apresentada como uma barreira - atenção dividida entre professor e intérprete professor fala enquanto anda, se volta para escrever no quadro, o que dificulta leitura labial do surdo;

Dificuldades não podem ser atribuídas diretamente aos alunos - elas se devem as ações e hábitos do contexto educativo;

Professor e instituição devem desenvolver estratégias de integração do aluno e não o inverso;

As interações devem ser revistas também pelos alunos ouvintes - "relações em um contexto de diversidade".
ASPECTOS RELACIONADOS À LEITURA E À ESCRITA.

“Considerável quantidade de trabalho intelectual exigido - exige atividades de leitura, compreensão e expressão de conteúdos complexos";

Leitura e escrita são dois grandes desafios na universidade - nível de leitura não esperado para esta etapa;

Estudos evidenciam que estudantes surdos universitários apresentam baixos níveis de letramento e dificuldades na aprendizagem da leitura e escrita;

Há uma zona de tensão entre aluno surdo e professor;

Existem vários questionamentos: o que exigir de leitura e escrita? Onde começam e onde terminam as dificuldades acerca das diferenças linguísticas?

Há necessidade de problematizar tais questões para que não haja risco de subestimar ou superestimar as competências e habilidades do surdo;

Alunos surdos se sentem incomodados com 'avaliações' dos professores - "deficiência ou diferença? - o "susto" do professor causa malestar;

Aspecto que mais chama a atenção: dificuldade na leitura e escrita, muita das vezes, atribuída à trajetória anterior

Quadro 1: Evidências da Pesquisa (VALETIN; BISOL, 2012:55-71)

Fonte: Elaborado pela autora. 


\section{A experiência visual do surdo a partir do uso de artefatos}

Antes de destacar o design como um processo facilitador na experiência visual do surdo, é importante referenciar a 'experiência visual' em si. Para isto, foi adotado como princípio, uma descrição sucinta do termo 'linguagem visual' utilizado por Dondis (2007).

Não é difícil de detectar a tendência à informação visual no comportamento humano. Buscamos um reforço visual de nosso conhecimento por muitas razões; a mais importante delas é o caráter direto da informação, a proximidade da experiência real. (...) A experiência visual humana é fundamental no aprendizado para que possamos compreender o meio ambiente e reagir a ele; a informação visual é o mais antigo registro da história humana. As pinturas das cavernas representam o relato mais antigo que se preservou sobre o mundo tal como ele podia ser visto há cerca de trinta mil anos. (DONDIS, 2007:5,6)

Dondis (2007:3) afirma que, "a linguagem é simplesmente um recurso de comunicação próprio do homem, que evoluiu desde sua forma auditiva, pura e primitiva, até a capacidade de ler e escrever." Sobretudo, ela sugere que há uma "variedade de métodos de composição e design que levem em conta a diversidade da estrutura do modo visual".

Dondis (2007:9), relata como a linguagem tem mantido sua posição de destaque frente ao modo visual e tátil, devido sua capacidade de promover o aprendizado humano, de armazenar e mediar informações e ideias e auxiliar a mente humana no processo de conceituação. Sobretudo, Dondis (2007) ainda salienta que,

a sintaxe visual existe, e sua característica dominante é a complexidade. A complexidade, porém, não se opõe à definição. Uma coisa é certa. O alfabetismo visual jamais poderá ser um sistema tão lógico e preciso quanto a linguagem. As linguagens são sistemas inventados pelo homem para codificar, armazenar e decodificar informações. Sua estrutura, portanto, tem uma lógica que o alfabetismo visual é incapaz de alcançar. A tendência a associar a estrutura verbal e a visual é perfeitamente compreensível. Uma das razões é natural. Os dados visuais têm três níveis distintos e individuais: o input visual, que consiste de miríades de sistemas de símbolos; o material visual representacional, que identificamos no meio ambiente e podemos reproduzir através do desenho, da pintura, da escultura e do cinema; e a estrutura abstrata, a forma de tudo aquilo que vemos, seja natural ou resultado de uma composição para efeitos intencionais. (DONDIS, 2007:11)

Ao aplicar esta abordagem para no campo da surdez, é importante referenciar a língua utilizada no processo de comunicação dos surdos: a Língua de Sinais, considerada uma experiência visual para o surdo.

Segundo Strobel (2008:24) "dentro do povo surdo, os sujeitos surdos não diferenciam um de outro de acordo com grau de surdez, e sim o importante para eles é o pertencimento ao grupo usando a língua de sinais e cultura surda que ajudam a definir as suas identidades surdas." Além de ser reconhecida como parte essencial no processo pedagógico, a Língua de Sinais, através de sua condição viso-espacial, destaca a visualidade e é vista pelos surdos, como um artefato linguístico que os auxilia na apreensão da realidade de forma aflorada e verdadeira, fundamental na cultura surda.

A língua de sinais é uma das principais marca da identidade de um povo surdo, pois é uma das peculiaridades da cultura surda, é uma forma de comunicação que capta as experiências visuais dos sujeitos surdos, sendo que é esta língua que vai levar o surdo a transmitir e proporcionar-lhe a aquisição de conhecimento universal. (STROBEL, 2008:44) 
O Quadro 2, apresenta um retrato da linha do tempo do processo de educacional dos surdos ao longo dos últimos séculos.

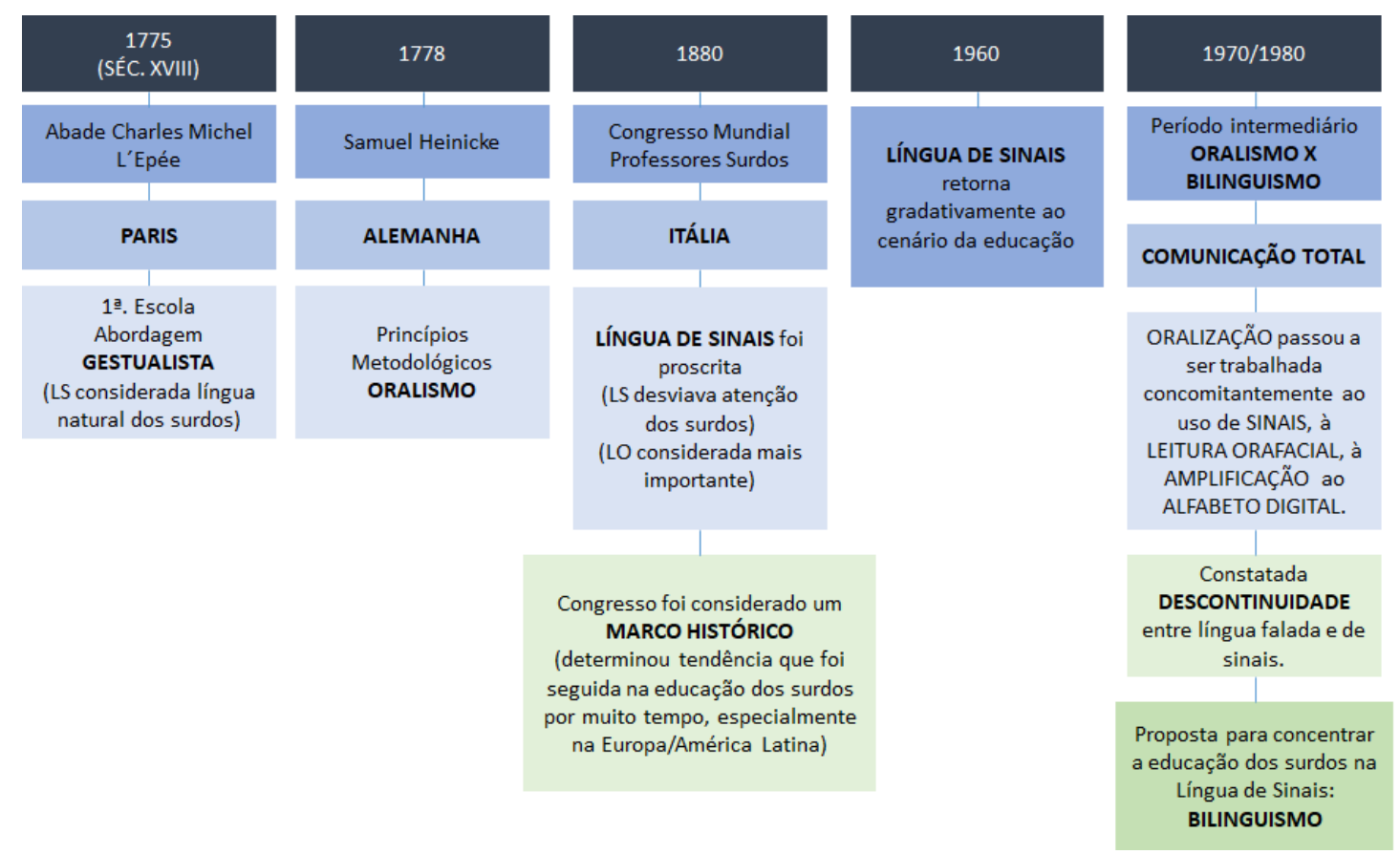

Quadro 2: Linha do tempo processo educacional do surdo por Pesquisa (VALETIN; BISOL, 2012:44,45)

Fonte: Elaborado pela autora.

Como é possível observar, a Língua de Sinais vem mostrando-se fundamental para o processo cognitivo e de aquisição da linguagem para o surdo, caracterizado um 'sujeito visual'. Segundo Strobel (2008:6), a experiência visual é considerada o primeiro artefato da cultura surda, ou seja, é quando "os sujeitos surdos percebem o mundo de maneira diferente, a qual provoca as reflexões de suas subjetividades."

Strobel (2008:15) ainda ratifica que, "inclusivamente os surdos oralizados também têm este artefato cultural visual, a maioria deles se apoia na percepção visual para ler nos movimentos dos lábios do interlocutor que articula as palavras e frases da língua portuguesa." Sendo assim, observa-se como a questão visual torna-se importante para os surdos, como pode influenciar seu processo cognitivo e o enriquecimento de suas interações socioculturais.

No Quadro 3, Strobel (2007) ainda faz um comparativo entre a representação social e a representação de povo surdo.

REPRESENTAÇÃO SOCIAL

REPRESENTAÇÃO DE POVO SURDO

\begin{tabular}{|c|c|}
\hline Deficiente & "Ser surdo" \\
\hline A surdez é deficiência na audição e na fala & Ser surdo é uma experiência visual \\
\hline $\begin{array}{l}\text { A educação dos surdos deve ter um caráter clínico-terapêutico e } \\
\text { de reabilitação }\end{array}$ & $\begin{array}{l}\text { A educação dos surdos deve ter respeito pela diferença linguística } \\
\text { cultural }\end{array}$ \\
\hline $\begin{array}{l}\text { Surdos são categorizados em graus de audição: leves, moderados, } \\
\text { severos e profundos }\end{array}$ & As identidades surdas são múltiplas e multifacetadas \\
\hline A língua de sinais é prejudicial aos surdos & $\begin{array}{l}\text { A língua de sinais é a manifestação da diferença linguística relativa } \\
\text { aos povos surdos }\end{array}$ \\
\hline
\end{tabular}

Quadro 3: Comparativo entre representação social e representação de povo surdo.

Fonte: Strobel (2007:32). 
Taveira; Rosado (2017:17) relatam em sua pesquisa-ação que, "ir a campo observar o saberfazer do sujeito-ator ${ }^{1}$ surdo no papel de instrutor ${ }^{2}$ nos trouxe a hipótese de que a experiência visual surda tem um sentido de letramento."

O Quadro 4, abaixo listado, apresenta algumas das evidências relatadas por Taveira; Rosado (2017) durante sua pesquisa:

\section{PONTOS RELEVANTES DA PESQUISA}

\begin{abstract}
Foram identificadas insuficiências de base teórica em matrizes de linguagem (visual, verbal e sonora) - Há um distanciamento do conteúdo didático-visual;

Necessário investigar práticas pedagógicas dentro do enfoque bilíngue;

Para ler imagem deve haver um desmembramento da mesma;

A adequação de objetos ao meio cultural e social também tem influência na comunicação e no processo de ensino e aprendizagem - Há um acréscimo de recursos digitais;

Para o professor ouvinte as formas figurativas são dominantes. Para o professor ou instrutor surdo, além das formas figurativas, há inserções de formas representativas, que em alguns casos tornam-se dominantes;

Para o instrutor ou professor surdo - o letramento visual é nitidamente diferente - murais mais visuais;

Ser letrado para o sujeito-ator surdo significa: artista e professor são uma colagem justaposta; língua portuguesa perde papel central, ganha espaço a oralidade, a sinalidade e o visual; é necessário o desenvolvimento da acuidade visual e do potencial expressivo; alguns dos professores ou instrutores surdos possuem um feeling sobre o letramento visual;
\end{abstract}

Observar, classificar, catalogar os artefatos surdos que combinam com o uso da visualidade é um imperativo na atualidade.
É importante desconstruir práticas pedagógicas de territórios ouvintes - Abrir mão da disputa entre línguas;

Apelo imagético acrescenta outros olhares ao letramento, à leitura, à escrita e à produção literária;

Empoderamento de professor surdo e ouvintes nas escolas por meio do acesso à diversidade de estilos e modos de expressão da cultura de ambos;

Explorar o design como ferramenta acessível à construção de diferentes técnicas visuais;

As metáforas surdas são consideradas o hibridismo entre as matrizes de linguagem, sonora, visual e verbal. Portanto ainda estamos distante da informação de que há a incidência do verbal, do simbólico, nas metáforas surdas;

Vale ressaltar que a Libras não há homogeneização da Libras e da cultura surda brasileira - a língua está sujeita às variações regionais;

O arranjo imagético de uma sala de aula com incidência da experiência de um surdo adulto, da didática surda, é dominado pelo uso da extensão do corpo;

Confirmam importância do domínio da escrita da língua de sinais, ou das fotografias e dos vídeos em um futuro próximo para as salas de aula;

Quadro 4: Evidências da Pesquisa Taveira; Rosado (2017).

Fonte: Elaborado pela autora.

Diante disto, infelizmente, é visível como as reais particularidades da cultura surda ainda estão aquém da total percepção sensível do ouvinte. Sobretudo, é possível entender como os processos de significação, envolvem tanto a 'aquisição da linguagem', quanto a capacidade de abstração do significado/aquisição da mensagem, o que se faz parte relevante ao desenvolvimento cognitivo do indivíduo.

Ao se tratar dos processos de significação e aquisição da linguagem pelos surdos, entende-se que, uma linguagem visual que utilize de ferramentas acessíveis e didáticas, aliadas às tecnologias da informação através de ferramentas multimídias com recursos visuais e/ou vibratórios, intérpretes e/ou legendas, torna possível promover uma conexão comunicacional assertiva entre surdo e ouvinte.

Para Lebedeff (2010:179), "conceitos como cultura surda, experiência visual e cultura visual remetem, consequentemente, ao conceito de letramento visual".

Ao ser referenciado o 'apelo imagético' na educação de surdos, observa-se a relevância do desenvolvimento de uma sensibilidade interpretativa voltada para a decodificação e o entendimento do significado da mensagem, o que poderá fazer com que o surdo se sinta familiarizado com os elementos visuais ali dispostos e assim, desenvolva a capacidade de abstração, ou decifração desta mensagem.

Taveira; Rosado (2017:30) elucidam que, "observar, classificar, organizar (catalogar) os produtos da prática pedagógica dos surdos (artefatos) que combinam com o uso da visualidade é um

\footnotetext{
${ }^{1}$ Alguns instrutores surdos têm como diferencial um conjunto de práticas pedagógicas que revelam uma didática diferenciada, uma invenção surda, em que o letramento visual ocupa lugar central. (TAVEIRA; ROSADO, 2017:18)

${ }^{2}$ Podemos referendá-lo como professor, visto que exerciam ações para tal efeito de ensino. (TAVEIRA; ROSADO, 2017:17)
} 
imperativo na atualidade." Taveira; Rosado (2017:32), apresentam no resultado de sua entrevista e observação de campo, como seria uma aula idealizada por um professor surdo. Segundo os autores, o planejamento acontece de forma diferenciada, o instrutor surdo opta em realizar seu planejamento explorando o uso de imagens. Para eles é,

algo que se aproxima à arte e à criação no campo da estética, mais do que no campo da didática. Perguntamos a este professor surdo se ele conhecia a técnica do storyboard ${ }^{3}$. Observamos que ele fez cursos de Design Gráfico e que havia uma espécie de making off de seus artefatos (quadrinhos, charge). Desta forma, faz sentido mostrar ao instrutor surdo que o esboço usado pelo artista gráfico também poderia ser um modo de planejamento realizado por ele, pois pareceu que enxergava as partes ou unidades visuais das cenas, das etapas de uma aula, como em uma visão panorâmica. (TAVEIRA; ROSADO, 2017:32)

Diante disto, vale ressaltar as percepções de Guarinello et. al (2009:101), que também abordam o letramento e surdez, contudo no contexto universitário, considerando que, a alfabetização e letramento são termos próximos, sendo que a alfabetização faz uso de um código e técnicas de leitura e escrita, e o letramento, é considerado "a atividade efetiva da tecnologia da escrita, a qual envolve a possibilidade de ler e escrever para cumprir objetivos diversos: informar, interagir com o outro, fazer uma declaração, contar uma história, ampliar conhecimentos, orientar-se, divertir, entre outros."

A pesquisa de Guarinello et. al (2009:99) faz parte do Núcleo de Estudos "Surdez, Linguagem e Educação", ligado ao Mestrado e Doutorado em Distúrbios de Comunicação da Universidade Tuiuti do Paraná. Tal pesquisa, tem como objetivo destacar as condições de letramento de estudantes universitários surdos, de forma a investigar o desempenho destes alunos em práticas de leitura e escrita. A pesquisa foi feita através de dois instrumentos de coleta de dados: a) questionários com questões abertas e fechadas; e b) seis textos de diferentes gêneros textuais, a serem lidos e formuladas respostas mediante interpretação de seus conteúdos.

Foram entregues 70 questionários, mas apenas 20 alunos responderam. Estes 20 alunos que participaram da pesquisa são alunos de diferentes cursos de Graduação em Universidades da cidade de Curitiba, sendo que, um deles, é aluno do curso de Graduação em Letras - LIBRAS de Florianópolis. Foi destacado que $75 \%$ dos participantes, frequentou escola regular, e $25 \%$, escola especial. Hoje, $45 \%$ destes 20, cursam Letras/Libras e os demais, estão inseridos em diferentes áreas como: Medicina, Desenho Industrial, Educação Física, Design Gráfico, Design de Moda, Administração, Psicologia e Pedagogia.

Este estudo tem como objetivo, destacar como resultado da pesquisa de Guarinello et. al (2009:110,111) que, 90\% dos estudantes surdos afirmaram ter o hábito da leitura, sobretudo, os autores destacaram que a metade destes participantes fazem uso de recuso multimídia para permitir o acesso a recursos visuais (animação de imagens e sinais gráficos) na busca pelo auxílio da compreensão do conteúdo durante tais leituras.

Visto isto, compreende-se a importância da integração do design ao processo educacional do surdo. Ainda, vale relembrar a pesquisa de Taveira; Rosado (2017), que também apresentou a importância de se compreender a experiência visual a partir do 'letramento visual e produção de artefatos', todavia tendo seu foco, na fase escolar do sujeito surdo. Assim, é possível entender que, a extensão desta prática, também se faz relevante na fase acadêmica, sobretudo, com um olhar dinâmico, fazendo uso de técnicas singulares, de forma a explorar recursos visuais legitimados às especificidades do aluno surdo no contexto acadêmico.

\section{0 design como facilitador na experiência visual do surdo}

Neste primeiro momento, é importante fazermos referêcia a um pensamento de Bonsiepe (2012:24), que descreve como "o design tem uma função imprescindível que consiste em integrar a ciência e a

\footnotetext{
${ }^{3}$ Roteiro imagético usado no planejamento de filmes, seriados e documentários. (TAVEIRA; ROSADO, 2017:32)
} 
tecnologia na vida cotidiana de uma sociedade, com foco na interseção entre o usuário e o produto ou informação". Para ele,

a popularização do design durante a década de 1980 transformou a palavra 〈design $\mathrm{em}$ um termo multiuso. Seria hipócrita queixar-se desse fato; porém, a popularização leva a uma visão distorcida. Frequentemente, usa-se o termo 〈design〉 como etiqueta para uma classe especial de produtos, por exemplo, designer jeans, designer joias e designer móveis... Esses exemplos tendem a esconder o fato de que todos os artefatos materiais e semióticos são resultados de atividades projetuais, e não somente aqueles produtos para a decoração doméstica e a autorepresentação pessoal que levam a etiqueta 〈design . (BONSIEPE, 2011:35)

Neste contexto, o design pode ser visto como um processo comunicacional e informacional, que prima por um olhar sensível ao real conteúdo da apresentação visual de mensagens. É uma atividade de múltiplas facetas, voltada para o social, que tem como foco, a promoção do bem estar coletivo. Frascara (2004) afirma que,

design is an intellectual, sensitive, and practical discipline, requiring many levels of human activity: power of analysis, sensitivity to difference, mental flexibility, interpersonal skills, clarity of judgment, visual sensitivity, cultural awareness, and technical knowledge. ${ }^{4}$ (FRASCARA, 2004:207)

Imrie; Hall (2001:10), destacam o design como um mediador das relações sociais e das práticas acessíveis. Para eles, a prática do design tem refletido novos comportamentos e expectativas frente às barreiras físicas, compostas por barreiras sociais e de atitude, destacadoras da diferença.

Assim, também vale referenciar a influência do design frente aos processos linguísticos, cognitivos, e a concepção da experiência visual do indivíduo, pois sua abordagem mediadora, acaba por promulgar o desenvolvimento das interações sociais, culturais, educacionais e profissionais, fazendo com que sejam devidamente articulados processos que visam a alteridade, a acessibilidade, a inclusão e a construção da autonomia do indivíduo.

Entende-se que, o design tem como premissa, a ética, o bem estar e a melhoria das experiências psicossociais, cognitivas e sensoriais. Ademais, é importante tratar o design, como um processo relacional que visa promover a quebra de paradigmas, olhares mais sensíveis, novas articulações e a fundamentação da essência do indivíduo, de forma a abrir horizontes e novas possibilidades para uma melhor compreensão das diferenças. Para Bonsiepe (2012),

no momento, o estado cognitivo do design está coberto por um véu de dúvidas, desenrola-se no domínio visual, intrinsecamente relacionado com a experiência estética e menos com o domínio discursivo. Ao contrário de outras disciplinas universitárias, o design não se orienta, prioritariamente, para a geração de novos conhecimentos científicos, mas visa às práticas da vida cotidiana. O design enfoca o caráter operacional dos artefatos materiais e semióticos, interpretando a sua função e a funcionalidade não em termos de eficiência física, como acontece nas engenharias, mas em termos de comportamento incorporado em uma dinâmica cultural e social. (...) O design não é, em termos filosóficos, um accidens. Não se pode agregá-lo a nada, pois é intrínseco a cada artefato. É essentia. (BONSIEPE, 2012:20-21)

O design é realmente capaz de efetivar experiências sociais transformadoras, que visam novas dinâmicas sociais e uma reconfiguração social mais justa e participativa, moldada por ações que buscam suscitar uma nova consciência de mundo, principalmente com foco na inclusão e mediação.

\footnotetext{
4 O design é uma disciplina intelectual, sensível e prática, que exige muitos níveis de atividade: poder da análise, sensibilidade à diferença, flexibilidade mental, habilidades interpessoais, clareza de julgamento, sensibilidade visual, consciência cultural e conhecimento técnico. (FRASCARA, 2004:207, tradução nossa)
} 
Manzini (2017:43), destaca que o conhecimento advindo da prática do design tem se difundido cada vez mais. Para ele, o design tem sido visto "como um modo de pensar e um comportamento aplicáveis a inúmeras situações". Todavia, a gama de significados atribuídos ao design e às atividades advindas dele, têm gerado algumas "interpretações equivocadas em potencial". O autor ainda afirma que,

nos últimos anos, temos visto uma transformação rápida e de profundo alcance nos sistemas sociais e técnicos. O design, que, por sua própria natureza, preenche a lacuna entre eles, não poderia deixar de se transformar em suas raízes. O próprio design foi (e ainda é) um terreno fértil para a inovação social. Na verdade é um dos mais dinâmicos. (MANZINI, 2017:43)

Diante disto, ao trazer o foco para a educação inclusiva dos surdos, entende-se que, cabe aos designers, atuarem no papel de agentes transformadores, focados na promoção do bem estar coletivo e da acessibilidade, de forma que sejam exploradas, da melhor forma possível, as habilidades e competências advindas da prática desta atividade multifacetada e dinâmica. Sobretudo, ainda pode ser destacada, a importância da multiplicidade cultural da prática do design, que, ao fazer uso de influências colaborativas, acaba por promover um restabelecimento de significados e valores no tecido social, possibilitado ao indivíduo agir em consonância ao coletivismo e às boas práticas relacionais.

$\mathrm{O}$ design pode ser visto como um processo que envolve particularidades comunicacionais, tecnológicas, culturais e organizacionais, capazes de promover soluções dinâmicas, que vão além da prática de 'facilitar processos', ele envolve a cooperação mútua, o incitamento à criatividade e à ação do 'fazer acontecer'. Manzini (2017:54), trata a pesquisa em design como uma "atividade que produz conhecimento em design, isto é, produz o conhecimento necessário para fazer design." O autor ainda classifica esta pesquisa em dois tipos: a) "pesquisa para o design - é a pesquisa que produz melhores ferramentas conceituais e operacionais voltadas ao design"; e b) "pesquisa sobre o design - é a pesquisa que ajuda a compreender a natureza do próprio design."

Para Manzini (2017:80), "o design não é simplesmente um facilitador de processos".

O design é uma cultura específica, e especialistas em design deveriam ser selecionados por sua criatividade e treinados para o uso dessa criatividade na transformação da sua cultura de design em visões e propostas. Essa cultura de design e essa criatividade são o que especialistas em design deveriam trazer para a inovação social e para os processos de codesign que a sustentam. (...) Na verdade, codesign é um processo no qual todos podem apresentar ideias, muito embora essas ideias possam, às vezes, gerar problemas e tensões. No final, o que faz dessa complexa miscelânea de iniciativas um processo de design é o fato de que os atores envolvidos desejarão ouvir e serão capazes de ouvir uns aos outros, mudar de opinião e convergir para uma visão comum quanto aos resultados a serem obtidos. Em resumo, isso significa que eles desejam e são capazes de estabelecer uma cooperação dialógica. (...) Portanto, acredito que especialistas em design deveriam ser, ao mesmo tempo, críticos, criativos e dialógicos. (MANZINI, 2017: 80;81)

Visto isto, nota-se quão imensas são as possibilidades de, através do design, se construir pontes, de mediar os processos relacionais e comportamentais e promover experiências enriquecedoras, pois trata-se de uma atividade que vai muito além de se cumprir o briefing proposto em cada projeto, ela requer uma postura crítica e consciente, pautadas na atualidade, na compreensão histórica e cultural de cada processo. O design é antes de tudo, uma forma de linguagem, é um processo comunicacional propulsor de novos horizontes e conhecimentos, e que também deve estar diretamente ligado às questões sócio educacionais, em especial, às práticas pedagógicas inclusivas.

A prática do design abrange experiências ricas, envolvendo a materialidade, a imaterialidade, a percepção, os significados, as conexões entre informação, comunicação, tecnologia, questões sociais diversas, dentre outras. É importante que se tenha um olhar sensível, voltado para o incentivo no despertar da criatividade, da percepção e interpretação, da conexão entre experiência x sensibilidade no processo de observação, produção e criação, de forma a comprovar a relevância do empoderamento do design em todos. 
Ao falarmos sobre percepção e interpretação, vale ressaltar Lupton; Miller (2011) os quais afirmam que,

uma teoria do design que isola a percepção visual da interpretação linguística incentiva a indiferença em relação ao sentido cultural. Embora o estudo da composição abstrata seja, em si, irrepreensível, a linguística e os aspectos sociais do design são banalizados ou ignorados quando a abstração é colocada como foco principal do pensamento sobre design. (LUPTON; MILLER, 2011:62)

Lupton; Miller (2011:63) destacam a percepção a partir da experiência cultural. Segundo os autores, "na prática da vida cotidiana, no entanto, a percepção é filtrada pela cultura. O conceito de um objeto é tanto visual (espacial, sensorial, pictório) quanto linguístico (convencional, determinado por acordo social)." Para eles,

O termo "linguagem visual" é uma metáfora. Ele compara a estrutura do plano pictório à gramatica ou à sintaxe da linguagem verbal. $\mathrm{O}$ efeito dessa comparação é segregar a "visão" da "linguagem". Os dois termos são colocados como opostos análogos, mas irreconciliáveis, domínios paralelos educacionais nelas baseadas interromperam o estudo do sentido social e linguístico, isolando a expressão visual de outros modos de comunicação. Em nome da interpretação à frente da percepção, a "linguagem" pode ser compreendida de forma inclusiva e não exclusiva. Palavras, imagens, objetos e costumes, desde que ingressem no processo comunicativo, não ocupam classes separadas, mas participam do sentido cultural e historicamente determinado que caracteriza a linguagem verbal. (LUPTON; MILLER, 2011:65)

Mediante esta questão da conexão da linguagem com as experiências do indivíduo, Cardoso (2013:133) afirma que "um valor característico do bom design é a inventividade de linguagem. Todo trabalho de design envolve o emprego e a conjugação de linguagens, geralmente de ordem visual e/ou plástica." Para o autor, o design vai além da materialidade e industrialização, ele permeia diversos campos do conhecimento, atuando também como um processo interativo e mediador da comunicação, acessibilidade e experiência sensorial.

Dito isto, observa-se como o design está incorporado, mesmo que intrinsicamente, ou de forma sutil, às necessidades da educação inclusiva, pois é fato que este pode ser visto tanto como um processo acessível, sensorial, comunicacional, quanto facilitador para a realização da produção simbólica, a fim de que sejam contextualizadas as mensagens durante o processo de letramento visual. Taveira; Rosado (2017) afirmam que,

um designer pode utilizar diferentes técnicas visuais para relacionar forma e conteúdo: palavras, imagens, formas abstratas. (...) O objetivo seria harmonizar o verbal e o visual para transmitir informação, para a construção efetiva do conhecimento. (TAVEIRA; ROSADO, 2017:30-32)

O design, pode atuar como um elo entre a reprodução do conhecimento, a percepção e a comunicação, além de tornar possível o desenvolvimento de interfaces que facilitem tal processo. Ora, Cardoso (2013:104) ratifica tal afirmativa quando diz que, "as interfaces precisam ser projetadas. Aí entra a enorme importância histórica do design. As redes não nascem prontas nem se mantêm operacionais sozinhas. Elas dependem de planejamento e precisam de constante manutenção e ajuste." $\mathrm{O}$ autor afirma que,

o design é uma área informacional que influi na valoração das experiências (...) a maior e mais importante contribuição que o design tem a fazer para equacionar os desafios do nosso mundo complexo é o pensamento sistêmico. Poucas áreas estão habituadas a considerar os problemas de modo tão integrado e comunicante. (CARDOSO, 2013:130,132) 
Ao referenciar o design no campo informacional, vale destacar Ribas (2018) em sua Tese de Doutorado voltada para o público surdo. Esta pesquisa apresenta o design como um processo digital com foco no desenvolvimento de ícones acessíveis, que segundo o autor, na maioria das vezes são considerados incompletos ou inexistentes, por não atender às características específicas destes usuários. Segundo o Ribas,

atualmente é reduzida a produção de materiais de linguagem não verbal (imagens, ícones, figuras ou vídeos) para Web e computadores, adequadamente acessíveis ao público surdo. Nesse sentido, ressalta-se a importância do uso dos elementos gráficos icônicos para a Web e/ou sistemas digitais compreensíveis, a fim de gerar informações mais inteligíveis para este público. (RIBAS, 2018:20)

Sua pesquisa tem como objetivo, oferecer um conjunto de recomendações para que designers possam desenvolver estas ferramentas acessíveis, sobretudo, de forma adequada às necessidades do usuário surdo. Ribas (2018:7), dividiu o trabalho em três etapas: a) aplicação de questionário/ entrevista com surdos; b) levantamento de diretrizes existentes para desenvolvimento de ícones; teste e verificação da aplicabilidade dessas diretrizes; e c) entrevista com grupo focal de surdos sobre a experiência do usuário. A pesquisa, mostra uma participação direta do design na produção de artefatos digitais, os quais podem ser considerados ferramentas cognitivas capazes de aprimorar a experiência visual do surdo, fazendo com que haja um processamento significativo das informações recebidas.

$\mathrm{O}$ autor ainda expõe a importância dos designers estarem conectados às especificidades da cultura surda, para que sejam levados em consideração, os principais aspectos do processo de criação de elementos visuais que têm como finalidade, facilitar a visualização e o entendimento das informações processadas. Tal fato, remete ao resultado da pesquisa Guarinello et. al (2009:110,111), citado anteriormente, em que os participantes que têm o hábito da leitura, afirmam fazerem uso de recursos multimídia (animação de imagens e sinais gráficos) para a auxiliarem na compreensão do conteúdo durante tais leituras. Isto pode ser confirmado mediante afirmativa de Ribas quando elucida que,

o GIF animado apresenta o movimento cinematográfico demostrando uma ação, isto é, o GIF animado é dinâmico, e esse ponto é fundamental para os surdos entenderem a informação passada. Além disso, este trabalho também acrescenta que se esses ícones, imagens ou GIFs possuírem movimento, isso facilitará ainda mais a navegação deste público, pois agiliza o entendimento da informação passada, já que os textos, muitas vezes, são abstratos para os surdos, ressaltando a importância que deve ser dada ao design de ícones e/ou GIFs animados para sua navegação. Estes GIFs animados também podem ser LIBRAS ou analogia a destes sinais, quando a informação a ser passada for abstrata. (RIBAS, 2018:134)

Para ele, o fator cultural e cognitivo do surdo, devem ser considerados pontos determinantes no processo criativo do designer. Por fim, Ribas (2018:50) afirma que isto se deve ao fato de que, devido à ausência do input auditivo, os surdos acabam por captarem o significado da informação de forma tardia, ao contrário dos ouvintes. Contudo, o autor ainda salienta que, "isso não significa que o surdo possua capacidades orgânicas e biológicas diferentes que dos ouvintes. Pelo contrário, são as mesmas."

Com isto, entende-se que o design tende a se conectar à inúmeras possibilidades de atribuição e aquisição do conhecimento. Para Cardoso (2013:129) "o design é um campo essencialmente híbrido que opera a junção entre corpo e informação, entre artefato, usuário e sistema.” Para ele,

o design tende ao infinito - ou seja, a dialogar em algum nível com quase todos os outros campos de conhecimento. Em seu sentido mais elevado e ambicioso, o design deve ser concebido como um campo ampliado que se abre para diversas outras áreas, algumas mais próximas, outras mais distantes. (...) A grande importância do design reside, hoje, precisamente em sua capacidade de construir pontes e forjar relações num 
mundo cada vez mais esfacelado pela especialização e fragmentação de saberes. (CARDOSO, 2013:128)

\section{Conclusão}

Este estudo possibilitou uma melhor compreensão acerda da importância do design no processo de inclusão do surdo no ensino superior. Foram destacadas abordagens envolvendo o design como processo mediador, plural e facilitador no campo educacional inclusivo.

O foco da pesquisa foi apresentar como a contribuição do design para este processo inclusivo é imprescindível para uma experiência visual mais assertiva ao aluno surdo. E, por meio da análise das pesquisas de campo aqui mencionadas, concluiu-se que o processo de imersão no contexto cultural e educacional do surdo no meio acadêmico, faz-se cada vez mais necessária, pois é através deste processo observatório que se é possível chegar a um diagnóstico preciso e eficaz, dos problemas vivenciados pelos surdos nas instituições de ensino superior.

É importante que sejam compreendias as barreiras e dificuldades enfrentadas por estes alunos, todavia, é imprescindível que continuemos buscando soluções e inovações mais práticas e assertivas, que favoreçam não somente a permanência do aluno surdo na universidade, mas que haja a aquisição do conhecimento de forma estruturada e com propriedade.

Compreendeu-se sobretudo que, o design, além de atuar diretamente na estimulação dos sentidos, também evidencia, motiva comportamentos e faz valer os aspectos sensoriais e cognitivos do indivíduo, contribuindo para a possibilidade de uma reinvenção e ressignificação do modo de vida da sociedade. Sob esta concepção, e com um olhar desmistificado acerca das diferenças, é possível que sejam reformulados modelos psicossociais e valores preconcebidos.

\section{Design: a facilitator in visual experience of the deaf in higher education}

Abstract: The objective of this study is contrast the importance of design like an accessible and facilitating process in the visual experience of deaf students in higher education. For this, it's important that they are understood the barriers and difficulties faced by these students in their university experience. Some research results were presented, which evidence both the university experience, as well as the visual experience of these students. The results describe the needs for a sensitive and demystifying eye at the alliance between design and pedagogical practices aimed at the education of the deaf, until then focused on exclusively hearing's territories. Moreover, it is understood that the design, can act like a propellant of the visual experience of the deafh, as well as, a mediator of relational interactions between all involved in this educational process.

Keywords: design; inclusive education; visual experience; deafness; higher education.

\section{Referências Bibliográficas}

BISOL, Cláudia Alquati et al. Estudantes surdos no ensino superior: reflexões sobre a inclusão. Cadernos de Pesquisa, São Paulo, v. 40, n. 139, pág. 147-172, abril de 2010. Disponível em: <http://www.scielo.br/scielo.php?script=sci_arttext\&pid=S0100-15742010000100008\&lng=en\&n rm=iso>. Acesso em 28. Ago.2020. http://dx.doi.org/10.1590/S0100-15742010000100008.

BONSIEPE, Gui. Design como prática de projeto, Editora Blucher. São Paulo: 2012.

BONSIEPE, Gui. Design, cultura e sociedade, Editora Blucher. São Paulo: 2011.

CARDOSO, Rafael. Design para um mundo complexo, Editora Cosac Naify, 2013. 
DONDIS, D. A. Sintaxe da linguagem visual. 3. ed. São Paulo: Martins Fontes, 2007.

FRASCARA, Jorge. Communication Design: principles, methods and practice, Allworth. New York: 2004.

GUARINELLO, Ana Cristina et al. Surdez e letramento: pesquisa com surdos universitários de Curitiba e Florianópolis. Rev. bras. educ. espec. Marília, v. 15, n. 1, p. 99-120, Abr. 2009 . Disponível em: <http://www.scielo.br/scielo.php?script=sci_arttext\&pid=S1413-65382009000100008\&lng=en\& nrm=iso >. Acesso em: 05. Set. 2020. https://doi.org/10.1590/S1413-65382009000100008.

IMRIE, Robert; HALL, Peter. Inclusive design: designing and developing accessible environments, British Library. Londres: 2001.

LEBEDEFF, Tatiana Bolivar. Aprendendo "a ler" com outros olhos: relatos de oficinas de letramento visual com professores surdos. Cadernos de Educação (UFPel), v. 36, p. 175-196, 2010.

LUPTON, Ellen; MILLER, Abbott. Design, escrita, pesquisa: a escrita no design gráfico, Brookman. Porto Alegre: 2011.

MANZINI, Ezio. Design: quando todos fazem design: uma introdução ao design para uma inovação social, Editora Unisinos. São Leopoldo: 2017.

QUADROS, Ronice Müller de. Educação de surdos: a aquisição da linguagem, Editora Artmed. Porto Alegre: 1997.

RIBAS, Armando Cardoso. Diretrizes para desenvolvimento de ícones digitais acessíveis ao público surdo. Tese (Doutorado em Engenharia e Gestão do Conhecimento) - Programa de PósGraduação em Engenharia e Gestão do Conhecimento, Centro Tecnológico, Universidade Federal de Santa Catarina. Florianópolis, p. 220. 2018.

STROBEL, Karin Lilian. As imagens do outro sobre a cultura surda, Editora UFSC. Florianópolis: 2008.

STROBEL, Karin Lilian. Capítulo I. In: QUADROS, R. M.; PERLIN, G. (Org.). Estudos Surdos II. Petrópolis, RJ: Arara Azul, 2007. p. 18-37.

TAVEIRA, Cristiane Correia; ROSADO, Luiz Alexandre da Silva. O letramento visual como chave de leitura das práticas pedagógicas e da produção de artefatos no campo da surdez. In: LEBEDEFF, Tatiana Bolivar (org.). Letramento visual e surdez, Wak Editora. Rio de Janeiro: 2017:17-47

VALENTINI, Carla Beatris; BISOL, Cláudia Alquati. Inclusão no ensino superior: especificidades da prática docente com estudantes surdos, Editora Educs. Caxias do Sul: 2012. 